\title{
SIMPLIFIED METHODOLOGY FOR TESTING COMMON RAIL PIEZOELECTRIC INJECTORS TAKING INTO ACCOUNT REFERENCE CHARACTERISTICS
}

\author{
Tomasz Stoeck $^{1 *}$ - Karol Franciszek Abramek ${ }^{1}$ - Tomasz Osipowicz ${ }^{1}$
}

${ }^{1}$ Department of Automotive Engineering, Faculty of Mechanical Engineering and Mechatronics, The West Pomeranian University of Technology, Piastów 19 Ave., 70-310 Szczecin, Poland

\begin{tabular}{|c|c|}
\hline \multicolumn{2}{|l|}{ ARTICLE INFO } \\
\hline Article history: & The article presents the methodology \\
\hline Received: 04.06.2019. & Continental/Siemens VDO piezoelectric injectors. To determine \\
\hline Received in revised form: 08.11.2019. & the correctness of their operation, the reference characteristics \\
\hline Accepted: 11.11 .2019$. & were used, which, due to the lack of guidelines from the \\
\hline Keywords: & manufacturer, constituted the only reference base for the \\
\hline Piezoelectric injector & obtained expenses and the intensity of fuel overflows. \\
\hline Fuel dosage & Simultaneously, the phase of the active experiment was simplified \\
\hline Reference characteristics & by limiting the number of measuring points, and then estimating \\
\hline Polynomial interpolation & the missing data using the Aitken iterative technique. Automation \\
\hline Aitken triangular matrix & of the calculation process was obtained thanks to the proprietary \\
\hline DOI: https://doi.org/10.30765/er.1475 & $\begin{array}{l}\text { numerical algorithm, whose formulas were introduced into a } \\
\text { standard spreadsheet. }\end{array}$ \\
\hline
\end{tabular}

\section{Introduction}

Common Rail injectors are the most sensitive, that is susceptible to damage elements of fuel supply systems of self-ignition engines [1]. For this reason, more and more attention is paid to the problems of their regeneration [2]. This mainly applies to piezoelectric injectors as well as electromagnetic injectors of newer generations [3]. Nevertheless, such attempts are made, usually after positive results of the inspection as well as preliminary verification and the phase of diagnostic tests. It should also be emphasised that the effectiveness of the repair depends on many factors, including the nature of the detected defects, the degree of wear of individual components and assemblies, the values of the received doses and the intensity of overflows, etc. Damage to the main control and executive parts usually eliminates the tested injector from further operation on the engine [4]. In addition, the use of non-original replacements is not recommended, as it may contribute to accelerated consumption [5].

In the case of construction of piezoelectric injectors, performing the most technologically advanced split injection process [6], the key problem remains the lack of the possibility of replacing the stack of crystals controlling the work of the valve assembly. For this reason, the service covers a limited range of activities that come down to the washing phase and research assay. External contaminants are usually removed in ultrasonic baths, and persistent soiling and internal deposits are eliminated by thermochemical leaning at elevated detergent temperature [7]. In turn, checking the correctness of operation requires testing: electrical circuit, spraying, tightness, opening pressure and fuel dosage [8]. In the absence of manufacturer's base coordinates, the only reference for the obtained results are the reference characteristics, prepared on the diagnostic table for a specific group of brand new injectors. For this purpose, the average time of their driving is taken into account, but also the value of expenses at different working pressures. In this way, it is possible to assess the set of curves that are generated when testing injectors used. Since this process is very time consuming, it was decided to limit the number of measuring points and analytical estimation of missing data using the Aitken method.

\footnotetext{
* Corresponding author.

E-mail address: tstoeck@wp.pl
} 


\section{Methods}

\subsection{Research object}

The research object was piezoelectric injectors from Continental/Siemens VDO (Figure 1), which were dismounted from a four-cylinder, 1.6 D2 in-line engine with an operational mile of 157 thousand $\mathrm{km}$. It is a diesel unit, turbocharged with the Common Rail direct injection system, used to drive a Volvo C30 compact class passenger car.

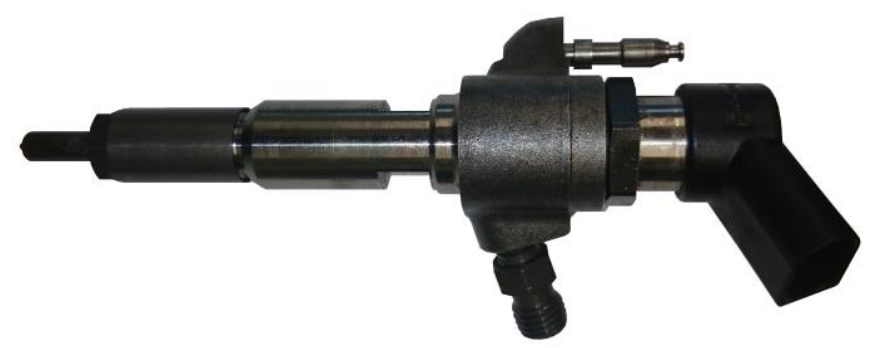

Figure 1. Continental/Siemens VDO piezoelectric injector.

For injectors of this type, the tightening torque of control valve and piezoelectric module is extremely important, since they have a direct impact on the correctness of fuel dosing [9]. In the absence of assembly data, the correct assembly of the injector is difficult even with the use of an electronic torque wrench. For this reason, such attempts are rarely undertaken when the external and internal cleaning stages do not bring the expected results.

\subsection{Reference characteristics}

Reference performance characteristics $E=f\left(p_{\text {inj }}\right)$ and corresponding fuel overflows $O=f\left(p_{\text {inj }}\right)$ were prepared on the basis of averaged measurement results of five brand new injector sets (20 pieces). A modular diagnostic table STPiW 3 from Autoelektronika Kędzia (Poznań, Poland) was used for this purpose (Figure 2). When generating curves, the following assumptions were taken into account: driving time $t=600 \mu \mathrm{s}$, range of working pressures $p_{\text {inj }}=20 \div 150 \mathrm{MPa}$.

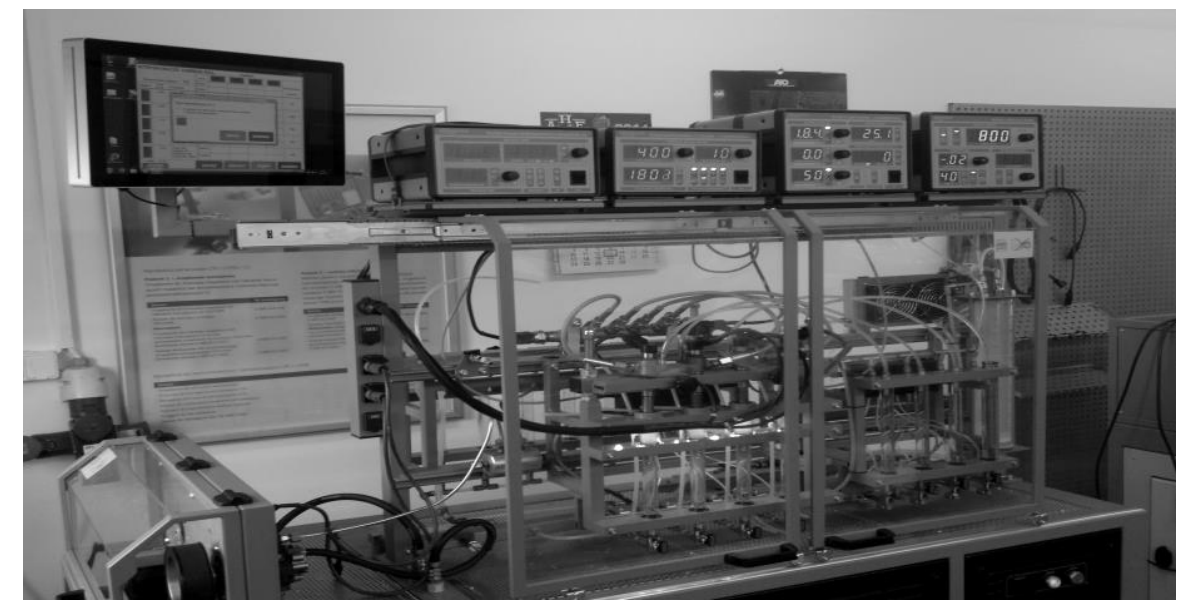

Figure 2. General view of the STPiW 3 diagnostic table.

Construction of the test bench allows simultaneous testing of four injectors. The fuel system has all the elements that can be found in a system of a car. The electric feed pump supplies calibration fluid through the filter to the high pressure pump (Bosch CP1). It is driven through toothed belt by the induction motor, powered by the inverter that provides smooth speed control. The pump is controlled by the cut-off valve and the pressure regulator valve. Tested injectors connected by flexible cables are placed in the injected fuel quantity measuring cylinders. On the right side test bench, there are glass burets that measure the return 
quantity. In order to maintain accuracy of the tests and comparability of the results, it is necessary to keep the fluid temperature constant. This is done by the system consisting of the heater, the electric pump and the cooler with the fan [10]. The results of the measurements can be observed in dose and return cylinders and tester's digital display. The bench alowes to prepare injector characteristics similar like in other research tables.

\subsection{Scope of research}

The tests of used injectors were carried out in two separate stages, which included the scope of preliminary and basic tests. The first one concerned basic electrical measurements, including the capacity of the piezoelectric module, its short to ground and the resistance of the circuit. The tightness control and the correctness of the fuel atomization were also carried out. As no irregularities were detected in this respect, they were qualified for testing on the assay table. In the generation of individual curves, the results of the active experiment were used, which was carried out at the following measurement points: 20, 50, 100 and $150 \mathrm{MPa}$. Function values in intermediate nodes were calculated after entering the obtained results into a spreadsheet. Prior to the basic testing phase, the injectors were washed externally in half-hour ultrasonic baths and then subjected to thermo-chemical cleaning on the STPiW 3 table.

\subsection{Aitken triangular matrix}

In 1932, Alexander Craig Aitken presented the iterative method, which made it possible to calculate the value of the Lagrange polynomial of the given point [11]. Its classic form is used to this day, because it does not require the presentation of the final pattern of the interpolating function [12]. Furthermore, addition or subtraction of subsequent nodes does not force a change to the previously prepared algorithm, which predisposes this technique in digital applications [13]. For the polynomial $W_{i, j}$ of the first degree, which in nodes $x_{i}, x_{j}(i \neq j)$ takes the values of $y_{i}, y_{j}$ it can be written as [14]:

$$
W_{i, j}(x)=\frac{\left[\begin{array}{ll}
y_{i} & x_{i}-x \\
y_{j} & x_{j}-x
\end{array}\right]}{x_{j}-x_{i}}
$$

In the general form, equation (1) will take the form:

$$
W_{0,1, \ldots, k, m}(x)=\frac{\left[\begin{array}{ll}
W_{0,1, \ldots, k-1, k}(x) & x_{k}-x \\
W_{0,1, \ldots, k-1, m}(x) & x_{m}-x
\end{array}\right]}{x_{m}-x_{k}}
$$

Formula (2) allows to estimate the values of the interpolation polynomial for any intermediate point. For this purpose, an Aitken triangular matrix (3) is created for the array of arguments and the corresponding function values [15].

$$
\left[\begin{array}{ccccccc}
x_{0} & y_{0} & & & & \\
x_{1} & y_{1} & W_{0,1} & & & \\
x_{2} & y_{2} & W_{0,2} & W_{0,1,2} & & \\
x_{3} & y_{3} & W_{0,3} & W_{0,1,3} & W_{0,1,2,3} & \\
\cdots & \cdots & \cdots & \cdots & \cdots & & \\
X_{N} & Y_{N} & W_{0, N} & W_{0,1, N} & W_{0,1,2, N} & \ldots & W_{0,1,2,3, \ldots, N}
\end{array}\right]
$$

\section{Analysis results and discussion}

Tables 1 and 2 present the results of preliminary tests that were carried out before the cleaning phase of the injectors. 
Table 1. Injector expenditures (fuel dosage) obtained in tests and preliminary calculations.

\begin{tabular}{|c|c|c|c|c|c|}
\hline \multirow{2}{*}{$P_{\text {inj }}$} & \multicolumn{5}{|c|}{$E$} \\
\cline { 2 - 6 } & $\mathrm{Nr} 1$ & $\mathrm{Nr} 2$ & $\mathrm{Nr} 3$ & $\mathrm{Nr} 4$ & $E_{\min } \div E_{\max }$ \\
\hline $\mathrm{MPa}$ & \multicolumn{5}{|c|}{$\mathrm{mm}^{3}$ injection } \\
\hline 20 & 5,2 & 6,3 & 5,3 & 5,9 & $5,8 \div 8,6$ \\
\hline 25 & 7,7 & 9,2 & 7,6 & 8,4 & $7,8 \div 11,6$ \\
\hline 50 & 17,1 & 20,3 & 16,9 & 18,2 & $18,2 \div 26,2$ \\
\hline 75 & 22,7 & 26,9 & 22,9 & 24,6 & $23,6 \div 32,6$ \\
\hline 100 & 25,8 & 30,6 & 26,7 & 28,8 & $27,7 \div 36,7$ \\
\hline 125 & 27,9 & 33,2 & 29,6 & 31,8 & $31,5 \div 40,1$ \\
\hline 150 & 30,3 & 36,2 & 32,6 & 34,8 & $34,3 \div 41,9$ \\
\hline
\end{tabular}

The admissible (boundary) limits have been established in relation to the values obtained in the preparation of the reference characteristics. The highest tolerability of dosing was assumed for $p_{i n j}=20 \div 25 \mathrm{MPa}$, because only in this area the improper cooperation of the precision pair (needle-sprayer) can be detected. At higher working pressures the impact of this failure is negligibly small and very difficult to observe [16]. For this reason, it was assumed that the value of expenditures and corresponding overflows will decrease gradually by $\pm 2 \%$.

Table 2. Injector overflows obtained in tests and preliminary calculations.

\begin{tabular}{|c|c|c|c|c|c|}
\hline \multirow{2}{*}{$p_{\text {inj }}$} & \multicolumn{5}{|c|}{$O$} \\
\cline { 2 - 6 } & $\mathrm{Nr} 1$ & $\mathrm{Nr} 2$ & $\mathrm{Nr} 3$ & $\mathrm{Nr} 4$ & $O_{\min } \div O_{\max }$ \\
\hline $\mathrm{MPa}$ & \multicolumn{5}{|c|}{$\mathrm{mm}^{3} /$ injection } \\
\hline 20 & 6,2 & 5,2 & 6,2 & 5,5 & $4,1 \div 6,1$ \\
\hline 25 & 7,2 & 6,1 & 7,2 & 6,4 & $4,6 \div 7,0$ \\
\hline 50 & 11,4 & 9,8 & 11,3 & 10,2 & $7,8 \div 11,2$ \\
\hline 75 & 15,2 & 13,2 & 15,0 & 13,8 & $10,5 \div 14,5$ \\
\hline 100 & 19,5 & 17,2 & 19,3 & 17,9 & $13,6 \div 18,0$ \\
\hline 125 & 25,5 & 22,5 & 25,2 & 23,5 & $19,4 \div 24,6$ \\
\hline 150 & 34,2 & 30,1 & 33,6 & 31,5 & $25,9 \div 31,7$ \\
\hline
\end{tabular}

Table 3. Injector overflows obtained in tests and preliminary calculations.

\begin{tabular}{|c|c|c|c|c|}
\hline$P_{\text {inji }}$ & $f\left(p_{\text {inji }}\right)$ & $W_{0, i}\left(p_{\text {inji }}\right)$ & $W_{0,1, i}\left(p_{\text {inji }}\right)$ & $W_{0,1,2, i}\left(p_{\text {inj }}\right)$ \\
\hline 20 & 5,2 & & & \\
\hline 50 & 17,1 & 27,0 & & \\
\hline 100 & 25,8 & 19,4 & 23,2 & \\
\hline 150 & 30,3 & 15,8 & 24,2 & 22,7 \\
\hline
\end{tabular}

The calculation method is shown on the example of the injector No. 1 at the intermediate point $p_{\text {inj }}=75$. In the first step, the triangular matrix (3) was brought to a tabular form, much more convenient for digital applications (Table 3). Nevertheless, regardless of the preferred presentation method, the positions on the left and in the row above were taken into account in the estimation of the values of the subsequent components. The last part is the wanted final result, i.e. the value of the interpolative polynomial for a given argument. To determine it, the dependence (2) was used, the formula of which was entered in the spreadsheet:

$$
E_{0,1,2,3}\left(p_{i n j}\right)=\frac{\left[\begin{array}{ll}
E_{0,1,2}\left(p_{i n j}\right) & p_{i n j 3}-p_{i n j} \\
E_{0,1,3}\left(p_{i n j}\right) & p_{i n j 4}-p_{i n j}
\end{array}\right]}{p_{i n j 4}-p_{i n j 3}}
$$

After substituting the numerical values, the value of the expenditure sought was obtained, which was presented in table 1: 


$$
E_{0,1,2,3}(75)=\frac{\left[\begin{array}{ll}
23,2 & 100-75 \\
24,2 & 150-75
\end{array}\right]}{150-100}=22,7
$$

The missing data for the set of injectors in the preliminary test was estimated in an analogous way. Their graphic interpretation in the form of characteristics $E=f\left(p_{\text {inj }}\right)$ and $O=f\left(p_{\text {inj }}\right)$ is shown in Figure 3.

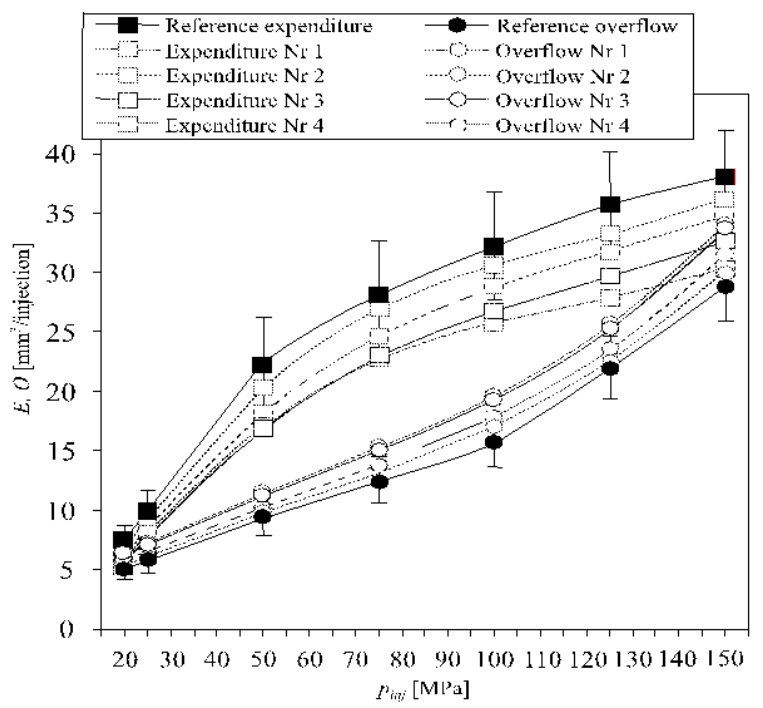

Figure 3. Preliminary characteristics: $E=f\left(p_{i n j}\right), O=f\left(p_{i n j}\right)$.

Analyzing the individual curves it can be seen that the admissible ranges were exceeded for injectors No. 1 and No. 3. However, their course, despite the observed deviations, remains close to the reference characteristics. This does not indicate the occurrence of more serious defects in the control and executive units, although at this stage of research it cannot be ruled out that the cooperation of precision pairs will worsen. It is also worth emphasizing that the reduction of expenditures and the simultaneous increase in the intensity of overflows were observed in the entire examined area, and their intensification became particularly noticeable at injection pressures of $p_{\mathrm{wtr}}=100 \div 150 \mathrm{MPa}$.

This may indicate a reduced dynamic of the work of individual actuators, which transfers to a change in the dosage method and excess flow [17]. The most likely cause of such a phenomenon is the presence of internal IDID deposits (Internal Diesel Injector Deposit) [18].

This has an adverse effect on the slowdown of the clipping time, mainly due to the delayed reaction of the needle to the electric impulse [19]. In addition, during the operation, the process of gradual coking of the nozzle tip [20] takes place, which additionally changes the geometry of the outlet holes (nozzles) [21]. As a result, there is a diversification of the amount of fuel injected into the engine cylinders [22].

Table 4. Expenditure of injectors (fuel dosage) obtained in tests and basic calculations.

\begin{tabular}{|c|c|c|c|c|c|}
\hline \multirow{2}{*}{$P_{\text {inj }}$} & \multicolumn{5}{|c|}{$E$} \\
\cline { 2 - 6 } & $\mathrm{Nr} 1$ & $\mathrm{Nr} 2$ & $\mathrm{Nr} 3$ & $\mathrm{Nr} 4$ & $E_{\min } \div E_{\max }$ \\
\hline $\mathrm{MPa}$ & \multicolumn{5}{|c|}{$\mathrm{mm}^{3} /$ injection } \\
\hline 20 & 6,1 & 6,6 & 6,3 & 6,5 & $5,8 \div 8,6$ \\
\hline 25 & 8,7 & 9,6 & 9,0 & 9,5 & $7,8 \div 11,6$ \\
\hline 50 & 19,0 & 21,1 & 19,4 & 20,8 & $18,2 \div 26,2$ \\
\hline 75 & 25,7 & 27,8 & 26,0 & 27,3 & $23,6 \div 32,6$ \\
\hline 100 & 29,8 & 31,6 & 30,1 & 31,2 & $27,7 \div 36,7$ \\
\hline 125 & 32,5 & 34,2 & 33,0 & 33,6 & $31,5 \div 40,1$ \\
\hline 150 & 35,0 & 37,0 & 35,9 & 36,4 & $34,3 \div 41,9$ \\
\hline
\end{tabular}

After cleaning the injectors, baseline tests were performed. The results obtained are summarized in Tables 4 and 5 and their graphical representation in Figure 4. 
In none of the considered measurement and calculation points, exceeded limit values were found. In addition, the course and shape of the plotted characteristics is very comparable. It should be concluded, therefore, that the malfunction was due only to the presence of impurities and persistent deposits that were removed during the thermo-chemical washing on the test bench. In such cases, it is suggested to replace the fuel filter, as well as rinsing the tank and the entire supply system in the vehicle [23]. In extreme cases, primarily related to the presence of metal filings, it may be necessary to replace all fuel distribution elements [24]. This guarantees the correct operation of the injectors during further operation on the engine, provided that the dates of periodic servicing and the use of high quality diesel oils are met.

Table 5. Injector overflows obtained in tests and basic calculations.

\begin{tabular}{|c|c|c|c|c|c|}
\hline \multirow{2}{*}{$p_{\text {inj }}$} & \multicolumn{5}{|c|}{$O$} \\
\cline { 2 - 6 } & $\mathrm{Nr} 1$ & $\mathrm{Nr} 2$ & $\mathrm{Nr} 3$ & $\mathrm{Nr} 4$ & $O_{\min } \div O_{\max }$ \\
\hline $\mathrm{MPa}$ & \multicolumn{5}{|c|}{$\mathrm{mm}^{3}$ injection } \\
\hline 20 & 5,6 & 5,0 & 5,4 & 5,2 & $4,1 \div 6,1$ \\
\hline 25 & 6,5 & 5,9 & 6,3 & 6,1 & $4,6 \div 7,0$ \\
\hline 50 & 10,4 & 9,6 & 10,1 & 9,8 & $7,8 \div 11,2$ \\
\hline 75 & 13,7 & 13,0 & 13,5 & 13,2 & $10,5 \div 14,5$ \\
\hline 100 & 17,5 & 16,9 & 17,4 & 17,1 & $13,6 \div 18,0$ \\
\hline 125 & 23,0 & 22,1 & 22,7 & 22,3 & $19,4 \div 24,6$ \\
\hline 150 & 31,3 & 29,4 & 30,2 & 29,6 & $25,9 \div 31,7$ \\
\hline
\end{tabular}

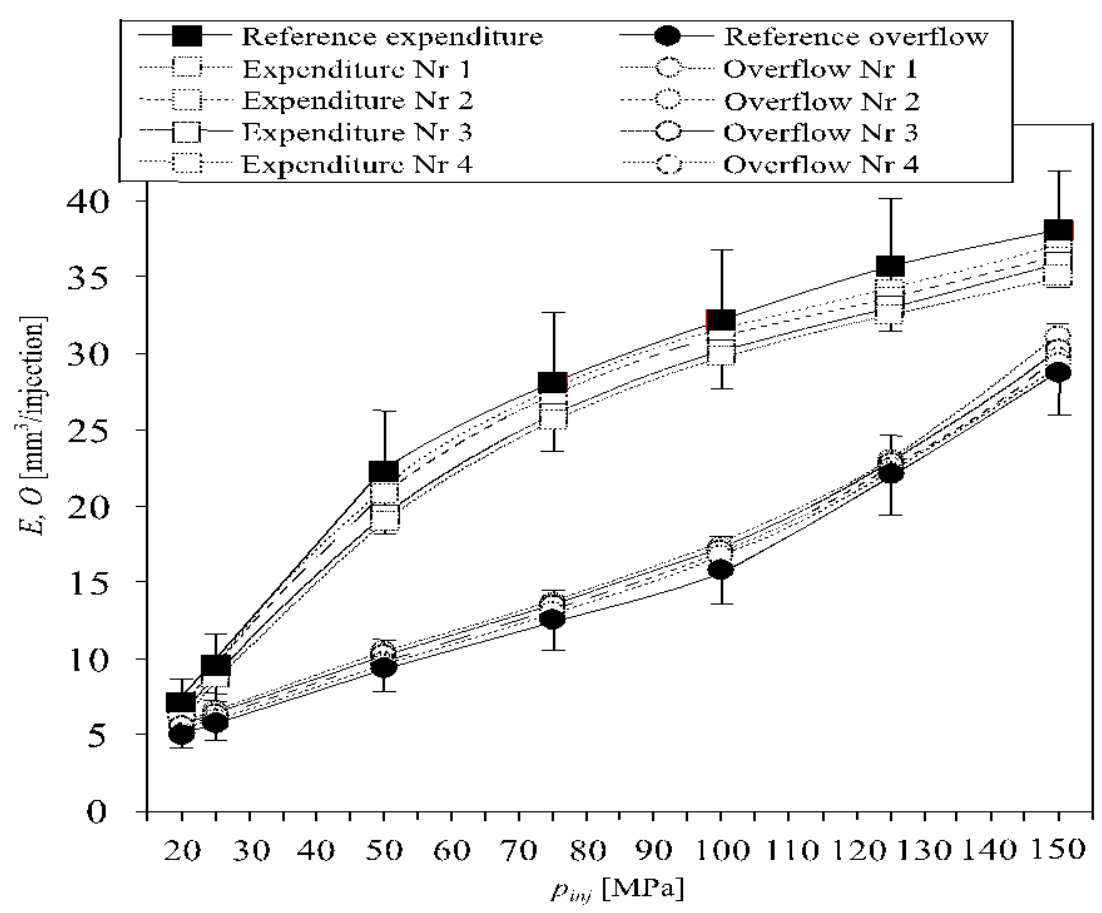

Figure 4. Basic characteristics: $E=f\left(p_{\text {inj }}\right), O=f\left(p_{\text {inj }}\right)$.

The STPiW 3 diagnostic table enables simultaneous testing of a set of injectors, provided that fully automated production procedures are used [25]. However, conducting tests at manual settings of operating parameters is more intensive, as all characteristics must be prepared separately. In this respect, the implementation of Aitken interpolation has brought tangible benefits. Considering that the time needed to perform a single injector test was $t_{\mathrm{p}}=4200 \mathrm{~s}$, the limitation of the number of measuring points and estimation of missing data allowed to obtain the result of $t_{\mathrm{p}}=2520 \mathrm{~s}$ (with calculation time equal to $t_{o}=120 \mathrm{~s}$ ).

Table 6. Comparison of measurement results and analytical calculations.

$$
\begin{array}{c|c|}
P_{\text {inj }} & E \\
\hline
\end{array}
$$




\begin{tabular}{|c|c|c|c|c|c|}
\hline & $\mathrm{Nr} 1$ & $\mathrm{Nr} 2$ & Nr 3 & $\mathrm{Nr} 4$ & $E_{\min } \div E_{\max }$ \\
\hline $\mathrm{MPa}$ & \multicolumn{5}{|c|}{$\mathrm{mm}^{3} /$ injection } \\
\hline 25 & 8,7 & 9,7 & 8,9 & 9,5 & \multirow{2}{*}{$7,8 \div 11,6$} \\
\hline $25^{*}$ & 8,7 & 9,6 & 9,0 & 9,5 & \\
\hline 75 & 25,6 & 27,9 & 25,9 & 27,3 & \multirow{2}{*}{$23,6 \div 32,6$} \\
\hline $75^{*}$ & 25,7 & 27,8 & 26,0 & 27,3 & \\
\hline 125 & 32,4 & 34,3 & 33,2 & 33,6 & \multirow{2}{*}{$31,5 \div 40,1$} \\
\hline $125^{*}$ & 32,5 & 34,2 & 33,0 & 33,6 & \\
\hline \multirow{2}{*}{$P_{\text {inj }}$} & \multicolumn{5}{|c|}{$O$} \\
\hline & $\mathrm{Nr} 1$ & $\operatorname{Nr} 2$ & Nr 3 & $\mathrm{Nr} 4$ & $O_{\min } \div O_{\max }$ \\
\hline $\mathrm{MPa}$ & \multicolumn{5}{|c|}{$\mathrm{mm}^{3} /$ injection } \\
\hline 25 & 6,6 & 6,0 & 6,3 & 6,2 & \multirow{2}{*}{$4,6 \div 7,0$} \\
\hline $25^{*}$ & 6,5 & 5,9 & 6,3 & 6,1 & \\
\hline 75 & 13,7 & 12,9 & 13,3 & 13,2 & \multirow{2}{*}{$10,5 \div 14,5$} \\
\hline $75^{*}$ & 13,7 & 13,0 & 13,5 & 13,2 & \\
\hline 125 & 23,1 & 22,2 & 22,7 & 22,2 & \multirow{2}{*}{$19,4 \div 24,6$} \\
\hline $125^{*}$ & 23,0 & 22,1 & 22,7 & 22,3 & \\
\hline
\end{tabular}

Table 6 summarizes the results of measurements on the test bench and analytical calculations. It can be seen that they are very similar.

\section{Conclusion}

The proposed methodology has simplified the process of generating the dosage characteristics of Continental/Siemens VDO piezoelectric injectors. In this respect, the choice of Aitken interpolation resulted mainly from the ease of implementation in the digital environment. The triangular matrix can be treated as the starting base for further analyzes, because any change in the number of main nodes does not force modification of the original algorithm, but only shortening or overwriting existing formulas. In addition, calculations carried out in any selected spreadsheet do not require the user to know the semantics and syntactic rules that are taken into account in modern programming languages and scientific-engineering applications.

The analysis was based on the results of measurements and analytical calculations that were carried out during preliminary and basic tests. The scope of necessary maintenance activities, taken into account in the next stages of regeneration, was also presented. Possible causes and effects of incorrect dosing of fuel have been specified, taking into account the actual operational course of the tested structures. In this respect, the work is a relatively rare occurrence, because the vast majority of available publications and studies are related to new injectors. In addition, the range of using the classic iterative technique was extended in an innovative way, which thanks to the implementation in the digital environment, has found practical application in laboratory and workshop conditions. This is due to the fact that the developed numerical algorithm is easy to modify and can be successfully used in testing injection equipment with a similar profile.

\section{References}

[1] Juściński, S., Piekarski, W., Chomik, Z.: Analysis of injection systems types used in agricultural machines, Agricultural Engineering, 21 (2017), 4, 37-46.

[2] Abramek, K. F., Stoeck, T., Osipowicz T.: Statistical Evaluation of the Corrosive Wear of Fuel Injector Elements Used in Common Rail Systems, Strojniški vestnik - Journal of Mechanical Engineering, 61 (2015), 2, 91-98.

[3] Karpiuk, W., Bor, W., Smolec R.: Possibilities of Analysis of Condition and Repair of Common-Rail System Injectors, Journal of KONES Powertrain and Transport, 23 (2016), 4, 209-216.

[4] Ignaciuk, P., Gil, L.: Damages to injectors in diesel engines, Advances in Science and Technology Research Journal, 8 (2014), 21, 58-61. 
[5] Nouraei, H., Ben-Mrad, R., Sinclair, A. N.: Development of a Piezoelectric Fuel Injector, IEEE Transactions on Vehicular Technology, 65 (2016), 3, 1162-1170.

[6] Stoeck, T., Osipowicz, T., Abramek, K. F.: Methodology for the repair of Denso Common Rail solenoid injectors, Eksploatacja i Niezawodność - Maintenance and Reliability, 16 (2014), 2, 270-275.

[7] Stoeck, T.: Implementing the principles of sustainability in automotive companies, Economics and Organization of Enterprise, 797 (2016), 6, 56-66.

[8] Kluczyk, M., Grządziela, A.: Vibration diagnostics of common rail injectors, Journal of Marine Engineering \& Technology, 16 (2017), 4, 177-184.

[9] Osipowicz, T., Abramek K. F.: Diagnosing methods common rail fuel injectors, Combustion Engines, 168 (2017), 1, 56-61.

[10] Kneba, Z., Straszak, P., Jakóbczyk, K.: The effectiveness of fault detection in common rail injectors examination methods, Combustion Engines, 170 (2017), 3, 49-56.

[11] Burden, R. L., Faires, J. D., Burden, A. M.: Numerical Analysis, Cengage Learning, Boston, 2016.

[12] Laskari, E. C., Meletiou, G. C., Vrahatis, M. N.: Aitken and Neville Inverse Interpolation Methods over Finite Fields, Applied Numerical Analysis \& Computational Mathematics, 2 (2005), 1, 100-107.

[13] Twyman, Q. J.: Interpolation schemes for valve closure modeling, Ingeniare. Revista chilena de ingeniería, 26 (2018), 2, 252-263.

[14] Fortuna, Z., Macukow, B., Wąsowski, J.: Numerical methods, Scientific and Technical Publications WNT, Warsaw, 2015.

[15] Rosloniec, S.: Fundamental Numerical Methods for Electrical Engineering, Springer-Verlag, Berlin Heidelberg, 2008.

[16] Pietras, D., Knefel, T., Satława, M.: The experimental determination of the relationship between the energizing time of the common rail injector and the set fuel quantity and rail pressure, MATEC Web of Conferences, 118 (2017), 00033, 1-6.

[17] Magno, A., Mancaruso, E., Vaglieco, B. M.: Experimental investigation in an optically accessible diesel engine of a fouled piezoelectric injector, Energy, 64 (2014), 842-852.

[18] Hoang, A. T., Le, A. T.: A review on deposit formation in the injector of diesel engines running on biodiesel, Energy Sources, Part A: Recovery, Utilization, and Environmental Effects, 41 (2019), 5, 584599.

[19] Stępien, Z.: A study of factors influencing the formation of harmful deposits in the diesel engine injectors, Eksploatacja i Niezawodność - Maintenance and Reliability, 19 (2017), 3, 331-337.

[20] Stanik, W., Jakóbiec, J., Mazanek, A.: Engine tests for coking and contamination of modern multiinjection injectors of high-pressure fuel supplies compression-ignition engine, Eksploatacja i Niezawodność - Maintenance and Reliability, 20 (2018), 1, 131-136.

[21] Pos, R., Wardle, R., Cracknell, R., Ganippa, L.: Spatio-temporal evolution of diesel sprays at the early start of injection, Applied Energy, 205 (2017), 391-398.

[22] Rounthwaite, N. J., Williams, R., McGivery C., Jiang, J., Giulliani F., Britton, B.: A Chemical and Morphological Study of Diesel Injector Nozzle Deposits - Insights into their Formation and Growth Mechanisms, SAE International Journal of Fuels and Lubricants, 10 (2017), 106-114.

[23] Jocanović, M. T., Karanović, V. V., Kneževic, M. M., Orošnjak, M. D.: Diesel fuel filtration problems with modern Common Rail injection systems, Vojnotehnički glasnik / Military Technical Courier, 65 (2017), 4, 968-993.

[24] Günther H.: Common - Rail - Systeme in der Werkstattpraxis. Technik, Prüfung, Diagnose, Krafthand Verlag Walter Schultz GmbH, Bad Wörihofen, 2012.

[25] Kneba, Z., Straszak, P., Jakóbczyk, K.: The effectiveness of fault detection in common rail injectors examination methods, Combustion Engines, 170 (2017), 3, 49-56. 